\title{
Editorial
}

\section{European Journal of Pediatric Surgery Reports}

\section{Mikko P. Pakarinen ${ }^{1}$}

${ }^{1}$ Children's Hospital, Helsinki University Central Hospital, Helsinki, Finland

Eur J Pediatr Surg Rep 2013;1:1-2.

You are looking at the very first issue of the European Journal of Pediatric Surgery Reports. This journal is devoted to case reports in all fields of pediatric surgery. It was chipped off from the mother journal to enable efficient editing and publication of the growing number of case report submissions, and it appears as both an online and a printed version. Case reports are in many ways the hard core of pediatric surgery, representing the endless number of very rare disorders, malformations and their different combinations often necessitating novel and previously unpublished treatment strategies. Many of these cases are clinically extremely interesting and important, but their rareness precludes reporting of broader studies. Furthermore, case reports are often the very first scientific communication written by a younger colleague.
This issue includes the first 21 reports originating from all over the world accepted for publication by our editorial board, consisting of pediatric surgeons from different parts of Europe with considerable scientific and clinical experience in the field. It has been a great pleasure to work with these professionals, whose work has made this journal possible. We received a large number of highquality case report submissions-unfortunately a lot more than could be published. It is time to thank all the authors of submitted articles for their interest toward this journal, my editorial board colleagues for fluent co-operation, and the publisher for editorial help. I hope you enjoy your reading!
Address for correspondence Mikko P. Pakarinen, Children's Hospital, Helsinki University Central Hospital, PO Box 281, FIN-00029 HUS, Finland (e-mail: risto.rintala@hus.fi). (c) 2013 Georg Thieme Verlag KG Stuttgart · New York
DOI http://dx.doi.org/ $10.1055 / \mathrm{s}-0033-1348059$. ISSN 2194-7619. 